\title{
ASSISTÊNCIA ESTUDANTIL: DELIMITAÇÕES HISTÓRICAS E O NOVO QUADRO NA CONJUNTURA BRASILEIRA
}

\author{
STUDENT AID: HISTORIC LIMITS AND THE CURRENT SITUATION IN BRAZIL
}

Glauco Pereira de Oliveira e Braga ${ }^{1}$

Keli Regina Dal Prá ${ }^{2}$

\section{RESUMO:}

O artigo aborda, por meio de revisão de literatura, o tema da assistência estudantil propondo, a partir de uma perspectiva histórica, a análise de sua conformação contemporânea na conjuntura brasileira. A assistência estudantil limitada, a partir de 2016, exprime uma nova fase no cenário nacional marcada pela austeridade fiscal determinada pelo Estado brasileiro. As reflexões realizadas pretendem consubstanciar uma ferramenta teórico-metodológica de análise para os trabalhadores e movimento estudantil das Instituições Federais de Ensino Superior sobre os rumos da assistência estudantil em face do quadro político-econômico que, ao afetar a educação superior, configura uma assistência estudantil limitada.

Palavras-chave: Política Social. Educação Superior. Assistência Estudantil.

\section{ABSTRACT:}

This article uses a review of the literature to examine student aid and a historic perspective to analyze the current situation of student aid in Brazil. The limited student aid imposed since 2016 express a new phase in the country marked by the fiscal austerity imposed by the Brazilian state. The reflections carried out intend to constitute a theoretical-methodological tool of analysis for workers and student movement of the Federal Institutions of Higher Education on the directions of student aid in the face of the political-economic framework that, by affecting higher education, constitutes a limited student aid.

Key-words: Social policy. Higher education. Student aid.

\section{INTRODUÇÃO}

A abordagem da assistência estudantil brasileira, neste artigo, situa-se a partir de sua terceira fase de formalização. Segundo Kowalski (2012), esta fase foi iniciada em 2007, no governo de Luiz Inácio Lula da Silva (Lula) entre os anos de 2003 e 2011, por meio da instituição do Programa de Reestruturação e Expansão das Universidades Federais (REUNI) cujas diretrizes estabelecem a ampliação da política de inclusão e de assistência estudantil.

\footnotetext{
1 Assistente Social. Núcleo de Assistência Estudantil da Universidade Federal de Santa Catarina (UFSC). Mestre em Serviço Social pela Universidade Federal de Santa Catarina. E-mail: glbraga7@gmail.com. ORCID: https://orcid.org/0000-0002-6585-6139.

2 Assistente Social. Doutora em Serviço Social pela Pontifícia Universidade Católica do Rio Grande do Sul. Departamento de Serviço Social da Universidade Federal de Santa Catarina (UFSC). E-mail: keliregina@yahoo.com. ORCID: https://orcid.org/0000-0002-1470-7811.
} 
"Essa fase se caracteriza por colocar a educação como um serviço, sendo que a formação acadêmica está voltada a atender à demanda do mercado” (KOWALSKI, 2012, p. 101).

Considerando a criação de mecanismos para a inclusão de uma parcela da sociedade que não acessava a universidade (ações afirmativas e interiorização da educação superior), bem como a necessidade de garantir a permanência por meio de dotação orçamentária, de ampliação da estrutura física das Instituições Federais de Ensino Superior (IFES) e do corpo de servidores, a assistência estudantil "vem construindo seu percurso histórico, trilhando-o, muitas vezes, por caminhos incertos e descontínuos, mas fazendo sua história na formação e consolidação das políticas públicas no país” (KOWALSKI, 2012, p. 102).

Vale ressaltar que a expansão da oferta do ensino superior público federal, na análise de Silva Júnior e Sguissardi (2013, p.144), se dá "sem o devido comprometimento do fundo público com a expansão de qualidade [...]", ocorrendo de forma precarizada, com estruturas institucionais e recursos humanos limitados e acentuando "ainda mais a histórica desigualdade sociocultural no país" mediante os direcionamentos político-econômicos de cunho neoliberal.

Compreende-se a assistência estudantil localizada no campo da discussão das políticas sociais, como conceito em disputa por projetos societários e ideológicos, principalmente pela perspectiva de educação a se alcançar a qual mediatiza a reprodução das relações sociais e, de forma contraditória, corrobora com uma educação nos limites do capital (BRAGA, 2018; 2019). É considerada como uma política no contexto do acesso à educação e de lutas sociais para se estabelecer uma universidade pública, gratuita, com ampliação de seu acesso por parte da classe trabalhadora, historicamente excluída do acesso à educação. A esse processo histórico se juntam a luta pela promoção de condições objetivas para a permanência dos estudantes ingressantes e o aprimoramento de políticas de ações afirmativas.

A conjuntura do país bem como as lutas e movimentos sociais em favor de uma educação pública, gratuita e para além do capital condicionam a formalização da assistência estudantil no Brasil. Inclusive as determinações econômicas, sociais e política, "[...] estão na base das teorias e ideologias" que por sua vez "[...] induzem tipos diversificados de proteção social nas diferentes fases do capitalismo", sendo a política social uma das expressões antagônicas dessa proteção social (PEREIRA, 2013, p. 23). Assim, se tensiona o projeto da assistência estudantil a qual exprime o movimento do capital para manter seu processo de acumulação capitalista.

O movimento histórico do capital tem requisitado aos setores de assistência estudantil um conjunto de profissionais para mediar, pelo trabalho coletivo, processos de seleção a fim 
de delimitar os discentes, público-alvo da assistência estudantil, por meio de entrevista social e/ou análise documental e para acompanha-los, marcados pelo recorte de renda, em face das condicionalidades estabelecidas para permanência nos programas. O caráter seletivo e focalizado da assistência estudantil reflete as orientações dos organismos multilaterais para a política de educação e demais políticas sociais. Essas são características das políticas neoliberais que, por sua vez, rebaterá no exercício profissional dos trabalhadores nas instituições de ensino superior, exigindo que busquem meios de contraposição a esta lógica amparados em um projeto profissional crítico.

O desafio posto aos profissionais, principalmente as/aos assistentes sociais, de se contrapor ao ideário neoliberal, aumenta com o processo de expansão da assistência estudantil nas IFES brasileiras, que desde meados da década de 2000, “vem inaugurando espaços sócioocupacionais para o Serviço Social enquanto uma das principais profissões responsáveis pelo planejamento e operacionalização da Política” (NASCIMENTO, 2013, p. 22). Assim, a/o assistente social tem se estabelecido como profissional chave nos setores vinculados as ações de assistência estudantil junto a outras profissões.

A proposição da abertura conceitual de uma nova fase da assistência estudantil, a partir de 2016, denominada assistência estudantil limitada (BRAGA, 2019), por meio de uma revisão de literatura, fundamentou-se na proposta do método histórico dialético no sentido de criar ferramentas "[...] cuja utilidade que se procura é a análise da realidade. Esses conceitos devem demonstrar sua eficácia como ferramentas de análise, isto é, provar seu poder explicativo" (DUMÉNIL, 2011, p. 224). A revisão bibliográfica buscou produções recentes, com ênfase em publicação de meados da década de 2010, período de mudanças políticas e econômicas no Brasil, que tratam de temas como assistência estudantil e política social, no sentido de estabelecer um estudo exploratório.

Tendo em vista a necessidade de se debater o tema da assistência estudantil o artigo ${ }^{3}$ soma forças na defesa de um projeto profissional histórico-crítico por meio do processo de análise do objeto por uma teoria social crítica a qual orienta a ação e o trabalho profissional, consubstanciando fundamentos de análise no viés crítico não fragmentando a leitura sobre a realidade da assistência estudantil. Dessa forma, propõe-se uma análise conjuntural da conformação contemporânea da assistência estudantil brasileira a qual estabelece uma

$3 \mathrm{O}$ artigo é fruto de revisão de uma parte teórico-reflexiva elaborada na dissertação intitulada Política Social e Família: uma análise a partir das universidades federais do sul do Brasil no contexto do Programa Nacional de Assistência Estudantil (PNAES) (BRAGA, 2019). 
"assistência estudantil limitada" no cenário nacional marcada pela austeridade fiscal determinada pelo Estado brasileiro.

\section{A ASSISTÊNCIA ESTUDANTIL E SUA TRAJETÓRIA NO BRASIL}

Segundo Kowalski (2012) há um processo de (des)caminho na caracterização da formalização da assistência estudantil brasileira pelo qual se propôs três fases a fim de sistematizar seu histórico. A primeira fase delimita-se ao período da criação da primeira universidade no Brasil se estendendo até o período de redemocratização política do país. A partir desse ponto inaugura-se a segunda fase que possibilitou uma organização da assistência estudantil por meio de lutas sociais, do movimento estudantil e de dispositivos legais. Em meados da década de 2000, a terceira fase se estabelece no período de expansão e reestruturação das IFES demarcando e caracterizando a assistência estudantil "até os dias atuais" (KOWALSKI, 2012, p. 82).

De forma geral, a primeira fase demarca-se pela concentração do acesso à educação à elite do país, pelo atendimento restrito aos alunos de classe média e pela formação voltada ao trabalho para o Estado. Não havia a presença, em âmbito nacional, de um programa direcionado para a assistência estudantil (KOWALSKI, 2012). Porém observa-se, em termos legais, a criação das primeiras universidades na década em 1930; a abertura nesse período da “Casa do Estudante do Brasill", no estado do Rio de Janeiro; a promulgação do Decreto n. 19.851, de 11 de abril de 1931 que dispõe sobre a estrutura do ensino superior brasileiro, apontando para a necessidade de estimular ações de assistência material e espiritual aos discentes, bem como iniciativas de caráter social por uma diretoria de estudantes de cada instituição; a inserção de artigo na Constituição Federal de 1934 estabelecendo dotações orçamentárias de fundos de educação para aplicar "em auxílios a alunos necessitados, mediante fornecimento gratuito de material escolar, bolsas de estudo, assistência alimentar, dentária e médica, e para vilegiaturas, ou seja, para períodos de recesso" (BRASIL, 1934, s/p); a criação da União Nacional dos Estudantes (UNE), em 1937; a criação da primeira Lei de Diretrizes e Bases da Educação (LDB), em 1961, por meio da Lei n. 4.024, de 20 de dezembro de 1961; e a criação do Departamento de Assistência ao Estudante (DAE) no regime militar, disposto no Decreto n. 66.967, de 27 de julho de 1970.

O período inaugural, desde a década de 1930 até a abertura democrática em fins da década de 1980, foi marcado pela delimitação dos primeiros instrumentos legais para a 
formalização da assistência estudantil mediante a luta de movimentos sociais, bem como pelas proposições governamentais e consolidou-se pelo “[...] caráter pontual, marcado pela escassez de recursos condizentes a reestruturação que a sociedade vinha passando e o novo formato que propunha a educação superior no Brasil [...]” (KOWALSKI, 2012, p. 158). A política de educação estava "relacionada aos direitos dos indivíduos à educação, à organização dos estudantes em centros voltados para sua adaptação e à participação no espaço acadêmico" (KOWALSKI, 2012, p. 101). Os benefícios monetários da assistência estudantil das instituições de ensino direcionados aos discentes não lograram êxito relevante no sentido de garantir eficazmente a permanência de estudantes na universidade (KOWALSKI, 2012).

Em 1987, após o regime militar, criou-se o Fórum Nacional de Pró-Reitores de Assuntos Comunitários e Estudantis (FONAPRACE) cujo objetivo desse fórum vincula-se à formulação de políticas e diretrizes para ações em âmbito regional e nacional de assuntos comunitários e estudantis.

A abertura democrática brasileira demarcou um período fundamental para a política social, principalmente, pela promulgação da Constituição Federal de 1988, com ênfase aos direitos sociais.

[...] mesmo com a democracia em vigência no país, o povo trazia as consequências dos longos e nebulosos anos de ditadura. Os problemas sociais tais como o desemprego, as deficiências nos serviços de saúde, as desigualdades na educação superior decorrentes das dificuldades de acesso e permanência persistiam. Esses movimentos de disputas se convergem e provocam mudanças na agenda política que, por sua vez, culminam na criação de novas políticas públicas (KOWALSKI, 2012, p. 93).

Houve a partir de 1990, no governo Fernando Collor de Mello, uma limitação de recursos no âmbito nacional para a assistência estudantil e as discussões sobre a sistematização dessa política ocorreram de forma fragmentada, restrita a uma parte das IFES. A LDB promulgada em 1996, no governo de Fernando Henrique Cardoso (FHC), não menciona nenhum tipo de financiamento para a assistência estudantil, a não ser a oferta de atendimento aos povos indígenas através de ações como a oferta de ensino e o estímulo à pesquisa e desenvolvimento de programas especiais (BRASIL, 1996; KOWALSKI, 2012). Ao final da segunda fase de formalização da assistência estudantil iniciou-se um processo de expansão do acesso ao ensino superior pela criação do Fundo de Financiamento Estudantil (FIES), em 1999, e do Programa Universidade Para Todos (PROUNI), em 2004. No âmbito da política de educação nacional demarca-se a aprovação do Plano Nacional de Educação (PNE).

Em síntese, a segunda fase da assistência estudantil foi marcada 
[...] por um período contraditório em relação ao primeiro, pois, há uma tendência na inclusão dos estudantes aos programas assistenciais resultante da demanda de alunos advindos do processo de democratização e expansão das vagas das IFES. Dessa forma, a educação superior tornou-se um dos maiores enfoques das políticas sociais. Também, foi neste momento histórico que teve uma maior ampliação dos projetos de assistência estudantil, como por exemplo, o investimento em moradias estudantis e RUs. Entretanto, não se evidenciou nas legislações em vigor, documentos que abarcassem e designassem recursos para o custeamento de programas socioeducativos; ao contrário, existiu um movimento de negação dos governantes em prover os recursos para a assistência estudantil, ratificado por meio da promulgação da LDB de 1996 (KOWALSKI, 2012, p. 158).

Apesar das ações de assistência estudantil ser concebidas desde 1930, elas tem forte legitimação por parte governamental no período de expansão das universidades federais, em meados da década de 2000, período que marca o início da terceira fase da assistência estudantil, sendo fruto de um movimento histórico balizado pela contrarreforma da educação superior (SANTOS; MARAFON, 2016; NASCIMENTO, 2013).

A assistência estudantil contemporânea conforma-se como uma das diretrizes do REUNI, instituído pelo Decreto n. 6.096, de 24 de abril de 2007 para criar condições de ampliação do acesso e permanência na educação superior, no nível de graduação. Essa vinculação expressa uma lógica mercadológica da universidade pública e condiciona a autonomia universitária (NASCIMENTO, 2013). De maneira geral se põe

[...] em prática uma política educacional que coloque em movimento a necessidade de criação de uma política científica e tecnológica eficiente e ao mesmo tempo um programa de certificação em massa e aparente qualificação profissional para o restante da população brasileira, tendo em vista a imposição nacional/internacional e a necessidade de aumento do exército de reserva de força de trabalho requerido pelo atual modelo de desenvolvimento econômico do país (SILVA JUNIOR; SGUISSARDI, 2013, p. 143).

Segundo Nascimento (2013), a assistência estudantil em seu processo de expansão, por meio de programas instaurados no governo Lula, conforma-se em uma fase renovada do neoliberalismo, no âmbito da contrarreforma universitária a qual carrega preceitos da reforma instaurada desde o Governo de Fernando Collor de Mello no início da década de 1990. A autora lança importante luz teórica ao período de expansão da assistência estudantil vinculado à agenda governamental de uma universidade operacional.

No âmbito da reforma universitária, o governo Lula dá prosseguimento às medidas contrarreformistas (privatização do ensino superior, fortalecimento das fundações de apoio, precarização do trabalho docente) que já vinham sendo implementadas, desde os governos Collor (1990-1992) e Cardoso (1995-2002). Contudo, a ênfase no discurso da democratização marca uma nova fase de contrarreformas que se desenrolam na gestão petista. É no 
interior das propostas 'democratizantes' levadas à cabo por programas como o REUNI, que a assistência estudantil é incorporada na agenda das 'reformas' do governo federal (NASCIMENTO, 2013, p. 14).

A fase expansionista da assistência estudantil inicia-se em 2007 na materialização da Portaria Normativa n. 39 de 12 de dezembro de 2007 (BRASIL, 2007), a partir do processo de implementação do REUNI, como fruto de um direcionamento político-econômico e ideológico de base neoliberal. No entanto, em 2010 esta portaria é substituída pelo Decreto n. 7.234 de 19 de julho de 2010, que dispõe atualmente sobre o Programa Nacional de Assistência Estudantil (PNAES).

Nesse período intensificam-se os fundamentos da "assistência estudantil consentida" enquanto projeto de assistência estudantil restritiva subscrita nos limites do projeto educacional dominante introduzindo a assistência à agenda governamental das contrarreformas universitárias. Ou seja, um projeto restritivo que a partir de sua expansão nos anos 2000 implicou mudanças substanciais do projeto de assistência estudantil historicamente defendido pelos movimentos sociais da educação (NASCIMENTO, 2013).

[...] a expansão da assistência estudantil (nos limites do projeto educacional dominante) serve à materialização do discurso de democratização, disseminado pelo Estado, e, sobretudo, funciona como mecanismo instrumental para garantir a produtividade da universidade de modelo operacional (NASCIMENTO, 2013, p. 20).

O último marco legal que dispõe sobre o PNAES como programa de governo, promulgado através do Decreto n. 7.234/2010, propõe à assistência estudantil ações a serem desenvolvidas em áreas como: moradia estudantil; alimentação; transporte; atenção à saúde; inclusão digital; cultura; esporte; creche; apoio pedagógico; e acesso, participação e aprendizagem de estudantes com deficiência, transtornos globais do desenvolvimento e altas habilidades e superdotação (BRASIL, 2010). Dentre os objetivos estão: democratizar as condições de permanência dos jovens na educação superior pública federal; minimizar os efeitos das desigualdades sociais e regionais na permanência e conclusão da educação superior; reduzir as taxas de retenção e evasão; e contribuir para a promoção da inclusão social pela educação (BRASIL, 2010).

Além disso, o documento estabelece em âmbito nacional que serão atendidos prioritariamente estudantes oriundos da rede pública de educação básica ou com renda familiar per capita de até um salário mínimo e meio, sem prejuízo de demais requisitos fixados pelas IFES (BRASIL, 2010). Dessa forma, consolida-se o "paradigma semirregulamentadoconcorrencial" da assistência estudantil que tem na legislação nacional a indicação de áreas 
prioritárias de ação permitindo que cada IFES organize e elabore as respostas sociais a partir de programas e ações de assistência estudantil particularizados (SANTOS, 2017).

Conforme o movimento histórico do capitalismo e os direcionamentos das políticas sociais mediante a dinamização do capital frente sua crise estrutural, apreende-se que a assistência estudantil relaciona-se diretamente às condições de permanência estudantil. Ou seja, refere-se às condições de viver e formas de viver no território e à conjuntura histórica, social e econômica que dinamizam as condições de subsistência da classe trabalhadora. A permanência envolve, entre outros aspectos, questões como:

[...] custo de transporte; distância entre residência e universidade; deficiência do ensino referente ao grau anterior; filhos para cuidar; falta de incentivo familiar; falta de acompanhamento psico-acadêmico; falta de vocação ou identificação com o curso escolhido; medo de greves; falta de informações acadêmicas; desorganização da instituição; falta de professores; excesso de disciplinas por período; dificuldade de aquisição de material didático, livros ou cópias xerografadas; falta de subsídios para se manter na instituição; falta de tempo para estudar; dificuldade nas disciplinas e de acesso à internet [...] (CRUZ FILHO et al., 2010, apud SILVA; NOGUEIRA, 2016, p. 119-120).

Como pressuposto para se abordar a assistência estudantil põe-se a importância de compreender, de forma ampliada, que a permanência estudantil, incluindo a questão do desempenho acadêmico, não se fundamenta na capacidade individual ou no aproveitamento de oportunidade, mas envolve questões socioeconômicas e históricas da trajetória e do cotidiano de vida dos discentes (IMPERATORI, 2017; BRAGA, 2019). Nesse prisma, a assistência estudantil sendo derivada da necessidade de permanência do estudante na instituição de ensino, se dinamiza pelas condições concretas de subsistência dos discentes o que implica na conjuntura da realidade social e de acesso aos direitos como a proteção ao trabalho, habitação bem como a presença efetiva de serviços sociais que garantam de fato uma materialização do direito à seguridade social.

A desconcentração do Estado, a partir das contrarreformas institucionais, provocou a transferência de responsabilidade estatal que no âmbito das universidades públicas impôs a estas à incumbência de executar atividades que não lhes eram pertinentes, tais como: "convênios com empresas privadas ou com associações de moradores para resolver problemas de violência, alfabetização de jovens e adultos, ensino de informática, formação de gestores e de líderes comunitários, etc.” (SILVA JUNIOR; CATANI, 2011, p. 102). Esse "novo paradigma" remete a um importante fundamento para se compreender a educação superior e compreender a assistência estudantil contemporânea, ditada em termos legais, nesse cenário. 
Os princípios elementares da contrarreforma do Estado se espraiam nas diversas políticas sociais e econômicas no Brasil. A educação tem sido demandada "pelo capital a reformar-se, assim como e primeiramente o Estado nacional" (SILVA JUNIOR; CATANI, 2011, p. 108). Com esse pano de fundo, situa-se no Ministério da Educação (MEC) o principal esforço de contrarreforma da educação superior nos anos recentes, que se verifica essencialmente mediante uma série de medidas de ordem legal (LDB, decretos, portarias, envio ao Congresso Nacional de medidas provisórias e de Propostas de Emendas Constitucionais) gerando consequências nefastas para a assistência estudantil.

Em suma, a educação superior no Brasil continua elitista e cada vez mais privatizada (SGUISSARDI, 2009). O desafio posto no horizonte seria compreender a educação superior brasileira que hoje se apresenta como um "sistema em crise de várias ordens - de hegemonia, de legitimidade e institucional [...]" (SGUISSARDI, 2009, p. 18). Conforme Nunes (2012, p. 241), um dos desafios basilares nessa modalidade de ensino a ser superado seria "a expansão de uma educação superior elitizada como a brasileira". Sendo assim, põe-se retoricamente a questão de "como alcançar a universalização da educação superior, ao mesmo tempo manter a qualidade do ensino, diante das restrições da estrutura social e da matriz profissionalizante que caracteriza a graduação brasileira [...]” (NUNES, 2012, p. 241).

O processo de formalização contemporânea da assistência estudantil, em suma, está imbricado na proposta da contrarreforma da política educacional brasileira materializada no programa REUNI e na conjuntura de implementação de medidas governamentais de caráter neodesenvolvimentista no Brasil. Esses processos históricos carregam direcionamentos da política econômica de ordem mundial que gera consequências nefastas para a sociedade e diretamente no cotidiano dos discentes, inclusive dos profissionais que atuam em ações de assistência estudantil, seja nas condições de trabalho, na racionalidade do trabalho, na subjetividade e nas relações sociais.

\section{A ASSISTENNCIA ESTUDANTIL LIMITADA: UMA NOVA FASE NA CONJUNTURA BRASILEIRA}

No caminho da formalização da assistência estudantil no Brasil, mediante posicionamentos políticos internos do governo federal, se têm intensificado a precarização do trabalho docente, a privatização do ensino superior e o corte nos orçamentos para a educação. Dessa forma, se dota de contradição a proposição da assistência estudantil na contribuição para o acesso à educação e à universidade pública como direito da classe trabalhadora. Nesse 
sentido, no contexto da mundialização financeira do capital e da exacerbação do capital fictício, em que a educação tem se tornado inclusive objeto de especulação financeira na bolsa de valores poder-se-ia propor o esboço de uma quarta fase da assistência estudantil, a partir de meados da década de 2016 até o momento atual.

A quarta-fase da assistência estudantil é demarcada pelo recesso do processo de expansão das universidades brasileiras, porém com a permanência e intensificação da lógica mercadológica imposta ao processo histórico de formalização da assistência estudantil, sendo fruto de intensas lutas políticas no Brasil ("impeachment" da presidenta Dilma Roussef e aprovação da Emenda Constitucional n. 95/2016), de instabilidade e regressão de direitos, inclusive de condições da permanência estudantil.

Considerando o cenário que demarca a instauração de um novo quadro conjuntural da assistência estudantil, mediante a dinâmica societária e contextual do país, apresenta-se a tendência de se formalizar uma assistência estudantil limitada (BRAGA, 2019). No cotidiano da realidade social na conjuntura da educação superior federal notam-se os rebatimentos na condição de vida dos estudantes e de suas famílias devido aos cortes orçamentários na educação pública, às contrarreformas administrativas do Estado e à limitação de gastos públicos intencionados pelo governo federal desde o mandato do Michel Temer (2016-2018) e intensificados pelo governo de Jair Bolsonaro iniciado em 2019. Dessa forma, estabelece-se uma intensificação de uma essência limitadora no movimento de formalização e desenvolvimento da assistência estudantil.

Temporalmente, a tendência categórica da quarta fase da assistência estudantil inaugura-se no mandato do ex-presidente Michel Temer. Nessa conjuntura percebe-se a limitação da assistência estudantil permeada por questões macroestruturais. Internamente as IFES respondem ao contexto por meio do enxugamento de contratos licitatórios, mudanças nos processos seletivos de ingresso, aumento na nota de corte em certos cursos tradicionais (direito, medicina e engenharias), restrição da oferta de serviços de assistência estudantil, remanejamento de auxílios estudantis, entre outras medidas que tensionam o acesso à universidade pela parcela mais pauperizada da sociedade constituída por negros, mulheres, indígenas e quilombolas. Retoma-se, assim, sutilmente a elitização da universidade pública, pela disposição de limitados recursos para a permanência e a abertura gradativa para privatização.

Essa nova fase, em processo de acirramento no âmbito nacional e local nas IFES, está balizada pela contrarreforma da educação brasileira, por concessões político-econômicas 
internas, coesão com as propostas de organismos financeiros mundiais e dilacerada pelo ideário neoliberal que mediante os serviços e programas vinculados à assistência estudantil direcionam ações seletivas, focalizadas e imediatas em face dos parcos recursos orçamentários. Acarretando assim, processos de trabalho excludentes em face da execução e operacionalização de programas de assistência estudantil, estabelecendo um "ambiente construído" disciplinador, nos termos de Harvey (1982).

A assistência estudantil limitada fundamenta-se de forma histórica e corrobora princípios e respostas promovidas pelo capital frente a sua crise estrutural, por meio do capital financeiro, instaurado no início da trajetória histórica da terceira fase, concomitante ao processo de expansão das universidades. Conforma-se pelo atual direcionamento dos cortes de gastos públicos instituídos em 2016 mediante a intensificação de medidas de acesso à universidade pública por meio do sistema ENEM/SISU (Exame Nacional do Ensino Médio e Sistema de Seleção Unificada) e da Política de Ações Afirmativas. Nesse cenário tem-se um número maior de acesso à universidade por uma parcela de estudantes com renda familiar per capita inferior a um salário mínimo e meio, oriundos de escola pública. Hoje $72 \%$ dos estudantes das IFES brasileiras encontram-se nessa condição socioeconômica (FONAPRACE, 2019). Além disso, ampliam-se nas IFES as reservas de vagas pelas ações afirmativas, porém sem recursos financeiros compatíveis a essa ampliação tampouco recursos físico-estruturais, profissionais entre outras necessidades para a permanência estudantil, considerando elementos como transporte, acesso à saúde, entre outras questões que influem diretamente nas condições de vida do estudante.

A Política de Ações Afirmativas, por meio da instauração da Lei Federal n. 12.711 de 29 de agosto de 2012 (lei de cotas), tem provocado nas conjunturas locais das IFES o aumento do acesso de discentes com o perfil de baixa renda. Outros grupos que têm sido privilegiados por medidas locais são as pessoas com deficiência e a população negra. Em relação ao primeiro grupo, preocupa as condições das universidades para estabelecer programas e profissionais de apoio para essas pessoas junto a uma estrutura física adequada. Se o crescimento não for acompanhado de condições mínimas estruturais e de serviços de permanência, limitar-se-á a permanência por um discurso ideológico de acesso e de dados quantitativos que carrega consequências drásticas para a constituição dos sujeitos históricos, principalmente para a classe trabalhadora e para a construção de uma educação gratuita de qualidade que de fato se vincula, em termos de proteção social, às necessidades básicas dos trabalhadores e ao direito à educação. 
A tendência da assistência estudantil limitada se expressa nas propostas governamentais a partir de 2016 como o corte proposto pelo MEC, em 2018, de bolsas para os estudantes indígenas e quilombolas. O Programa Bolsa Permanência, criado em 2013, também pelo MEC, direcionado aos discentes quilombolas e indígenas, corre o risco de caminhar para uma permanência limitada, não só pelas condições em que esta população já se encontra, mas pelo corte de condições imediatas de permanência. A luta é para se expandir a assistência estudantil, tanto no âmbito imediato quanto em lutas para romper com essa lógica do capital que tem dilacerado a educação e a condição de vida da classe trabalhadora brasileira.

Contemporaneamente, na conjuntura do governo do presidente Jair Bolsonaro, observa-se a retomada dos intentos propostos por Bresser Pereira, na década de 1990, de constituir a educação superior como serviço não-exclusivo do Estado ${ }^{4}$. Há uma série de medidas no âmbito governamental que afeta diretamente o acesso e a permanência nesse nível de ensino, nas IFES brasileiras, e principalmente o estabelecimento da universidade federal pública e gratuita.

O Programa Institutos e Universidades Empreendedoras, denominado, "Future-se" (BRASIL, 2019; UFBA, 2019) tem se constituído um instrumento político-legal do governo vigente para estabelecer um caminho para a privatização da universidade pública. Lançado em julho de 2019, tem como objetivo estabelecer parcerias com organizações sociais e o fomento à captação de recursos visando "reestruturar" o financiamento do ensino superior brasileiro. Anteriormente, no primeiro semestre de 2019, houve contingenciamento de dotação orçamentária para as universidades e institutos federais de educação por meio de dispositivos legais.

O MEC, em manifestação oficial sobre o orçamento de 2020, propõe às universidades que observem as legislações pertinentes e não promovam novos atos que aumentem as despesas com pessoal ativo e inativo, benefícios e encargos a servidores e empregados públicos em montantes em que o valor total não esteja devidamente autorizado (BRASIL, 2020).

\footnotetext{
${ }^{4} \mathrm{Na}$ institucionalização de serviços não-exclusivos do Estado, na proposta do ministro da Administração Federal e Reforma do Estado (MARE), Bresser Pereira, em meados da década de 1990, a universidade seria uma instituição primordial a ser transformada em entidade não estatal, o que tem ocorrido recentemente com os Hospitais Universitários, com os modelos de organizações sociais, e visaria a chamada modernização e aumento da eficiência pública. Assim, a educação superior, a área da ciência e tecnologia e a saúde eram consideradas como serviços não exclusivos do Estado e competitivos (SGUISSARDI, 2009).
} 
Entretanto, pretende-se destacar que esse processo geral de reorganização traduz consequências também no direcionamento das políticas sociais. Assim, no âmbito social ocorre a manifestação de programas focais (NUNES, 2012). As ações propostas na legislação que estabeleceu inicialmente o PNAES (BRASIL, 2007) por meio de portaria governamental, e posteriormente por meio de decreto (BRASIL, 2010) expressam a materialização dos ditames político-econômicos da trajetória histórico-política do Brasil nos caminhos da formalização da educação superior.

Sendo assim, conforme a dinâmica conjuntural do país do porvir a assistência estudantil pode sofrer transformações por meio de atualização de legislações com restrições à permanência estudantil balizada pela conjuntura de limitação orçamentária no contexto de austeridade fiscal, que farão com que as universidades reorganizem os programas de assistência estudantil. A assistência estudantil cuja perspectiva institucional caminha pari passu com as mudanças sociais e políticas dinamiza os princípios político-econômico e ideológico no viés social vinculado à política educacional brasileira estabelecendo-se como um conjunto de ações que forjam, assim como na discussão da política social, uma "cesta social" para a permanência constituída por "bens e serviços socialmente necessários à subsistência digna da pessoa, definidora do nível socialmente admissível de subsistência” (VIEIRA, 1992, p. 32).

A educação no Brasil e os caminhos da universidade pública acompanham a dinâmica social conjuntural do país. A assistência estudantil nesse sentido também está inserida nas mudanças ditadas pelos governos expressando tendências e perspectivas não aparentes desse movimento histórico. Sendo assim, os processos de contrarreformas correntes no contexto brasileiro mantêm a dinâmica político-econômica e ideológica do sistema de ensino superior e das demais políticas de educação superior decorrentes da conjuntura societária.

Considerando as restrições orçamentárias propostas por medidas provisórias e decretos governamentais, não só se restringe o direito à educação, também se limita as possibilidades de permanência estudantil no ensino superior mediante o contexto políticoeconômico que não favorece condições de vida dignas para os discentes das famílias pauperizadas da classe trabalhadora que são as que acessam majoritariamente políticas sociais com recortes de renda delimitando assim a fase contemporânea da assistência estudantil limitada.

\section{CONSIDERAÇÕES FINAIS}


Intentou-se demonstrar que a tendência do PNAES, a partir de sua quarta fase, é de uma maior focalização e corte das ações propostas como forma histórica de compensar os rebatimentos dos posicionamentos político-econômicos internos aliados ao desenvolvimento do capitalismo contemporâneo. Assim, seriam restritas as ações legalmente estabelecidas e o orçamento repassado pelo governo federal às IFES.

Poder-se-ia conceber pelo movimento histórico, agregando a contribuição de Nascimento (2013), a constituição de uma assistência estudantil consentida e limitada na ampliação do acesso à universidade e na garantia da permanência estudantil, tendência que precisa ser rompida de forma coletiva para tensionar sua limitação e sua restritividade, iniciando pela revogação da Emenda Constitucional n. 95/2016.

O movimento histórico no âmbito político, social e econômico junto ao tensionamento de lutas sociais e da organização e mobilização coletiva nas IFES bem como nos espaços de legitimação da política de assistência estudantil na contemporaneidade, como o FONAPRACE, dinamizarão essa nova fase, em processo de formalização e disputa, em face do direito à educação, do acesso e permanência no ensino superior público.

Por fim, mesmo não tratando das particularidades do trabalho profissional na assistência estudantil, as reflexões propostas coadunam com a visibilidade, a partir da abordagem histórica, das tendências contemporâneas sobre a conformação da assistência estudantil no Brasil, consubstanciando na reafirmação de fundamentos histórico-críticos a fim de se pensar desafios e estratégias aos profissionais inseridos no processo de reprodução das relações sociais mediada pela política social.

\section{REFERÊNCIAS}

BRAGA, G. P. de O. Política social e família: uma análise a partir das universidades federais do sul do Brasil no contexto do Programa Nacional de Assistência Estudantil (PNAES). 2019, 180 f. Dissertação (Mestrado) - Programa de Pós-Graduação em Serviço Social. Universidade Federal de Santa Catarina, Florianópolis, 2019. Disponível em: https://repositorio.ufsc.br/handle/123456789/214830. Acesso em: 31 mar. 2020.

BRAGA, G. P. de O. Programa Nacional de Assistência estudantil: fundamentos críticos e problematizações. Sociedade em Debate, Pelotas, v.25, n.2, p. 25-38, 2018.

BRASIL. Constituição da República dos Estados Unidos do Brasil de 16 de julho de 1934. Rio de Janeiro, $1934 . \quad$ Disponível em: http://www.planalto.gov.br/ccivil_03/Constituicao/Constituicao34.htm. Acesso em: 31 mar. 2020 . 
BRASIL. Lei n. 9.394, de 20 de dezembro de 1996. Estabelece as diretrizes e bases da educação nacional. Disponível em: http://www.planalto.gov.br/ccivil 03/leis/19394.htm. Acesso em: 30 mar. 2020.

BRASIL. Portaria Normativa n. 39, de 12 de dezembro de 2007. Institui o Programa Nacional de Assistência Estudantil - PNAES. Brasília, 2007. Disponível em: http://portal.mec.gov.br/arquivos/pdf/portaria_pnaes.pdf. Acesso em: 30 mar. 2020.

BRASIL. Decreto n. 7.234, de 19 de julho de 2010. Dispõe sobre o Programa Nacional de Assistência Estudantil - PNAES. Brasília, 2010. Disponível em: http://www.planalto.gov.br/ccivil_03/_Ato2007-2010/2010/Decreto/D7234.htm. Acesso em: 30 mar. 2020.

BRASIL. Ministério da Educação. Future-se. 2019. Disponível em: http://portal.mec.gov.br/busca-geral/12-noticias/acoes-programas-e-projetos-

637152388/78351-perguntas-e-respostas-do-future-se-programa-de-autonomia-financeira-doensino-superior. Acesso em: 30 mar. 2020.

DUMÉNIL, G. O projeto e o método. In: RENAULT, E.; DUMÉNIL, G.; LOWY, M. (orgs.). Ler Marx. São Paulo: Editora da UNESP, 2011, p. 211-234.

FONAPRACE. Fórum Nacional de Pró-Reitores de Assuntos Comunitários e Estudantis. V Pesquisa do perfil socioeconômico e cultural dos (as) graduandos (as) das IFES - 2018: Relatório executivo. Uberlândia (MG), 2019

HARVEY, D. O trabalho, o capital e o conflito de classes entre o ambiente construído nas sociedades capitalistas avançadas. Espaço e Debates, São Paulo, ano 2, n. 7, p. 6-35, set. 1982.

IMPERATORI, T. K. A trajetória da assistência estudantil na educação superior brasileira. Serv. Soc. Soc., São Paulo, n. 129, p. 285-303, maio/ago. 2017.

KOWALSKI, A. V. Os (des)caminhos da política de assistência estudantil e o desafio na garantia de direitos. 2012, 179f. Tese (Doutorado) - Programa de Pós-Graduação em Serviço Social. Pontifícia Universidade Católica do Rio Grande do Sul. Porto Alegre, 2012.

NASCIMENTO, C. M. Assistência estudantil e contrarreforma universitária nos anos 2000. 2013, 158 f. Dissertação (Mestrado) - Departamento de Pós-Graduação em Serviço Social. Universidade Federal de Pernambuco. Recife, 2013. Disponível em: https://repositorio.ufpe.br/handle/123456789/11438. Acesso em: 30 mar. 2020.

NUNES, E. de O. Educação superior no Brasil: estudos, debates, controvérsias. Com equipe e colaboradores do Observatório Universitário da Universidade Cândido Mendes. Rio de Janeiro: Garamond, 2012.

PEREIRA, C. P. Proteção social no capitalismo: contribuições à crítica de matrizes teóricas e ideológicas conflitantes. 2013, 307 f. Tese (Doutorado) - Programa de Pós-graduação em Política Social. Universidade de Brasília. Brasília, 2013. Disponível em: https://repositorio.unb.br/handle/10482/15153?mode=full. Acesso em: 31 mar. 2020. 
SANTOS, C. P. C. A assistência estudantil brasileira e a ação social portuguesa nas universidades públicas: do conhecimento à prática informada do Serviço Social. 2017, 396 f. Tese (Doutorado). Instituto Universitário de Lisboa. Departamento de Ciência Política e Políticas Públicas. Lisboa, 2017. Disponível em: https://repositorio.ufsc.br/xmlui/bitstream/handle/123456789/187211/PT0034T.pdf?sequence $=-1 \&$ is Allowed $=$ y. Acesso em: 30 mar. 2020.

SANTOS, C. P. C. dos; MARAFON, N. M. A política de Assistência Estudantil na Universidade Pública Brasileira: desafios para o Serviço Social. Textos e Contextos. Porto Alegre, v.15, n.2, p. 408-422, 2016.

SGUISSARDI, V. Universidade brasileira no século XXI: desafios do presente. São Paulo: Cortez, 2009.

SILVA JUNIOR, J. dos R.; CATANI, A. M. O financiamento da pesquisa no Brasil: sequestro do fundo público e da autonomia universitária. IN: SILVA JUNIOR, J. dos R.; CATANI, A. M.; MENEGHEL, S. M. (orgs.). A cultura da universidade pública brasileira: mercantilização do conhecimento e certificação em massa. São Paulo: Xamã, 2011, p. 95-110.

SILVA JUNIOR, J. dos R.; SGUISSARDI, V. Universidade Pública Brasileira no Século XXI: educação superior orientada para o mercado e intensificação do trabalho docente. Espacios en Blanco, Serie Indagaciones, $n^{\circ}$ 23, Junio, Buenos Aires, 2013, p.119-156. Disponível em: http://www.scielo.org.ar/pdf/eb/v23n1/v23n1a07.pdf. Acesso em: 30 mar. 2020.

SILVA, M. das G. M. da; NOGUEIRA, P. S. A permanência dos estudantes na educação superior para além da assistência estudantil. Rev. Fac. Educ. Mato Grosso, v. 25, n. 1, p. 111 129, 2016.

UFBA. Grupo de Pesquisa Trabalho, Precarização e Resistências Centro de Estudos e Pesquisas em Humanidades/CRH-UFBa. Dossiê sobre o programa future-se do governo/MEC e as implicações para a universidade e a sociedade. 2019. Disponível em: https://gtfuturese.paginas.ufsc.br/files/2019/08/Dossie\%CC\%82-FUTURE-SE-ufba.pdf. Acesso em: 30 mar. 2020.

VIEIRA, E. Democracia e política social. São Paulo: Cortez, 1992. 